\title{
EDUCAÇÃO E INDIVÍDUO PRAGMÁTICO NA CRISE CAPITALISTA CONTEMPORÂNEA
}

\author{
José Rômulo Soares ${ }^{1}$
}

\begin{abstract}
Resumo:
O presente trabalho discute a formação da individualidade pragmática no contexto da crise capitalista contemporânea, destacando a educação escolar e sua instrumentalização praticista às necessidades imediatas da lógica mercantil corrente na sociedade atual. Fundamentada em Mészáros apresenta o caráter estrutural da referida crise e suas consequências para o aprofundamento do individualismo competitivo da sociedade mercadológica hodierna. Ancorada em Heller, Vásquez e em outros pensadores marxistas, debate acerca da formação humana escolar sólida e comprometida com a emancipação do par dialético gênero-indivíduo, portanto, com novas formas de organização das relações sociais.
\end{abstract}

Palavras-chave: Educação, Indivíduo, Pragmatismo, Marxismo

\begin{abstract}
:
In this study we discuss the formation of the pragmatic individuality in the context of the contemporaneous capitalist crisis, with emphasis on schooling and how education is tuned to the immediate needs of today's mercantile logic. In light of the concepts of Mészáros, we describe the structural character of the capitalist crisis and its consequences for the strengthening of competitive individualism in the modern market- oriented society. Based on Heller, Vásquez and other Marxist thinkers, we discuss the possibility of a solid school-based education committed to the emancipation of the dialectic gender-individual dichotomy and, consequently, to new forms of organizing social relations.
\end{abstract}

Keywords: Education, Individual, Pragmatism, Marxism

\section{Caracterização da crise}

Nossa exposição tematiza as relações complexas e contraditórias entre educação escolar, indivíduo e sociedade, no contexto da crise capitalista contemporânea. Analisamos os fundamentos da sociedade erigida e administrada pela burguesia e seus

\footnotetext{
${ }^{1}$ Professor da Universidade Estadual do Ceará (UECE); Doutor em Educação, pela Universidade Federal do Ceará (UFC); Pesquisador vinculado ao Eixo Filosofia, Política e Educação, do Programa de Pós-graduação em Educação, da UFC. Membro do Grupo de Pesquisa Práxis, Educação e Formação Humana. E-mail: romulosoaresjr@yahoo.com.br
} 
colaboradores, a exemplo dos reformistas pragmáticos ${ }^{2}$, seu modelo escolar e a forma como esta classe dominante concebeu a individualidade nos marcos das relações sociais alienadas.

Elegemos como objeto de estudo o indivíduo forjado no processo histórico, com a colaboração da escola capitalista, que, na perspectiva da burguesia, serve de instrumento às tentativas de superação da crise em relevo.

Diante disto, situaremos, em linhas gerais, e nos limites de espaço desta exposição, o quadro gerador da crise atual e seus contornos mais significativos para efeito de nossa abordagem. Conforme Meszáros (2002), para além das aparências das explicações midiáticas correntes, a crise capitalista em ato encontra sua gênese na essência do próprio sistema, ancorado na propriedade privada, na divisão e na exploração do trabalho, na mercantilização da vida humana e natural, na produção destrutiva, dentre outros aspectos relevantes. Segundo o pensador marxista distintamente das crises cíclicas do capitalismo do passado, a crise contemporânea atinge de maneira profunda o sistema do capital, revelando-se como estrutural ou crônica.

Dessa maneira, o reformismo pragmático, seja na versão de John Dewey ou na de Richard Rorty, desconhece um fato adverso às vãs tentativas de humanizar as relações sociais capitalistas e de reformar a educação: de acordo com Mészáros, a crise estrutural revelou a incorrigibilidade do sistema do capital! Amparados na obra do filósofo húngaro, inferimos: a concentração e a centralização de riquezas, fundamento da lógica economicista-produtivista de reprodução ampliada do capital, impôs a desumanização dos seres humanos, criando e aprofundando contradições históricas, ora insolúveis sob sua própria forma de controle sóciometabólico, pondo os seres humanos num beco sem saída, pois, sob a égide do domínio do capital, somente nos resta a barbárie e a "( ) própria sobrevivência da humanidade" (MÉSZÁROS, 2003, p. 150) se vê ameaçada.

Para Mészáros, diante da extrema exploração da natureza e dos seres humanos, da contraditória convivência com ciclos viciosos de abundância e escassez e da produção destrutiva, o caráter civilizatório do capital atingiu seu apogeu, exigindo da humanidade

\footnotetext{
${ }^{2}$ O filósofo estadunidense John Dewey $(1859$ - 1952) figura como o maior expoente dos reformadores pragmáticos, no mundo. Em nosso país, Anísio Teixeira (1900-1971) destaca-se como seu mais notável representante. Na condição de reformuladores do pragmatismo, sob a forma de um neopragmatismo, distinguem-se o norte-americano Richard Rorty $(1931$ - 2007) e o brasileiro Paulo Ghiraldelli Júnior (1957).
} 
uma nova forma sociometabólica de organização da vida econômico-social e educacional: o socialismo.

De modo mais imediato, a crise em pauta, advém da década de 1970, com o prenúncio do colapso do Estado de Bem Estar Social, tornado fato nos anos 80, do século passado e de maneira mais clara, nos últimos meses de 2011, quando assistimos ao possível desmoronamento de economias consideradas sólidas pelos organismos de análise econômica, como as dos países da zona do euro, a exemplo da Itália, da Espanha, de Portugal e da França, após a recente tragédia grega ${ }^{3}$, vivida com dor e sangue, diante da qual, os escritos de Shakespeare parecem contos de fadas com final feliz.

Nesse momento crítico do capitalismo, devemos voltar nossa atenção para a grave crise nos Estados Unidos ${ }^{4}$, centro do império, inclusive para os movimentos sociais mobilizados contra o poder das grandes corporações e dos bancos, não somente nos Estados Unidos, como em mais de oitenta países. A título de provocação, lembramos que Mészáros (2003) sugere: por mais polêmico e surpreendente que possa parecer, o futuro do socialismo será decidido nos Estados Unidos. Os indignados ${ }^{5}$ de Wall Street apontam essa possibilidade?

Cumpre lembrar: após o fim do Estado de Bem Estar Social, o Estado mínimo para os interesses sociais e o Estado macro para os interesses do capital, funcionou como regra, na qual o capitalismo financeirizado afanou os cofres públicos, seja através de privatizações suspeitas, de empréstimos benevolentes, de calotes de dividas ou concordatas altamente rentáveis, ou ainda pela isenção de impostos, dentre outros métodos protecionistas do capital, aprofundando a crise. Ademais, a referida crise se distingue igualmente pelo desemprego estrutural ou crônico e pela dependência do capital da ajuda externa (estatal), que segundo Mészáros alcançou o limite sistêmico,

\footnotetext{
${ }^{3}$ Conforme dados publicados diariamente na imprensa mundial, informando acerca da imensa dívida grega, superior à totalidade das riquezas produzidas no país, concluímos que a Grécia quebrou. Após intensas lutas sociais, o país mudou de governo, recebeu vultosos empréstimos do Fundo Monetário Internacional - FMI e adotou reformas atacando diretamente os direitos e os salários dos trabalhadores. Os protestos continuam intensos na Grécia, apesar da repressão do Estado.

${ }^{4} \mathrm{O}$ país imperial também demonstra dificuldades: possui uma das maiores dívidas externas, do planeta, aumentada com novos empréstimos tomados em 2011, quando o presidente Barak Obama declarou não ter condições de pagar o funcionalismo público a partir de agosto daquele ano, caso não adquirisse novo empréstimo, aumentando a dívida do país; o crescimento anual dos Estados Unidos vem decrescendo e o desemprego alcança taxas preocupantes, dentre outros graves problemas de relevo.

${ }^{5}$ Referência aos manifestantes autonomeados de indignados, mobilizados nas manifestações denominadas ocupe Wall Street, ocorridas no maior centro comercial e financeiro do mundo, localizado na ilha de Manhattan, em Nova Iorque, Estados Unidos, em 2011. Na verdade, os indignados ocuparam diversas ruas dos Estados Unidos e do mundo, inclusive do Brasil, protestando contra as grandes corporações, segundo eles, detentoras de $99 \%$ das riquezas do planeta.
}

\begin{tabular}{|l|l|l|l|l|}
\hline Revista Dialectus & Ano 1 & n. 1 & Julho-Dezembro 2012 & p. 46-60 \\
\hline
\end{tabular}


pois, por sua vez, o Estado esgotou seus recursos ${ }^{6}$. Isto ocorre num contexto no qual as grandes corporações tornaram-se imensamente poderosas, verdadeiras proprietárias de Estados nacionais, decidindo sobre eleições de presidentes, governadores e prefeitos, como informa Pochmann, “(...) sugando como carrapatos, parcela crescente do orçamento público (...)” (POCHMANN, 2011, p. 7).

Entrementes, os trabalhadores pagaram e pagam as contas, vendo negados seus direitos básicos, inclusive o direito a uma educação integral, de tempo integral e transformadora. Aos mesmos, tem sido imposta uma educação limitada ao trato com saberes básicos e instrumentais aos interesses do capital em crise, por nós qualificada como uma educação para a ilusão de aprender a empreender com vistas ao sucesso individual, como advoga, por exemplo, a propalada pedagogia das competências em seu afã pragmático.

Nestes termos, o declínio do modelo taylorista-fordista e a assunção do modelo toyotista, nos anos 1980 e 1990, impôs uma nova pedagogia no chão da fábrica, propagando a flexibilidade da produção e do trabalhador, o trabalho em grupo, a criatividade e a participação. A constituição de uma nova subjetividade seria necessária com a colaboração, não somente dos trabalhadores, nas organizações, mas fundamentalmente da educação escolar, na qual a redefinição dos currículos e a formação dos professores despontam como aspectos estratégicos com vistas a atingir este fim. Nesses termos, a reabilitação do pragmatismo escolanovista, articulado com um tecnicismo renovado, responde às necessidades economicistas da chamada era digital, marcada por cursos aligeirados e à distância e pelo abandono dos conhecimentos clássicos das ciências, da filosofia e da arte, substituídos pelos saberes utilitários da experiência.

Fabrica-se, portanto, uma educação ideologizada e adaptativa, criadora de ilusões com o modus operandi empresarial, na qual o empreendedorismo se espraia de maneira vulgar e descolada da realidade, como ilustra o ensino técnico hoje propagado pelos organismos internacionais como a Organização das Nações Unidas - ONU e o Banco Internacional para Reconstrução e Desenvolvimento - BIRD (Banco Mundial - BM) e pelos governos nacionais e locais, a exemplo das escolas profissionalizantes de tempo

\footnotetext{
${ }^{6}$ Em alguns casos, a dívida de diversos países europeus alcança o nível do PIB. Noutros, a dívida estatal ultrapassa a soma das riquezas produzidas no país. O exemplo mais grave encontra-se na Grécia, na qual a dívida, já reduzida, após vários ajustes, alcança cento e sessenta por cento do PIB. Quanto à divida total da zona do euro, informações veiculadas em 06/02/2012, pela Revista Época, revelam que, no terceiro trimestre de 2011, a dívida da referida zona havia caído para 87,7 do PIB dos países membros.
}

\begin{tabular}{|l|l|l|l|l|} 
Revista Dialectus & Ano 1 & n. 1 & Julho-Dezembro 2012 & p. 46-60 \\
\hline
\end{tabular}


integral no Estado do Ceará, orientadas política e pedagogicamente pela Tecnologia Empresarial Socioeducacional - TESE, Uma nova escola para a juventude brasileira, elaborada conforme os princípios empresariais da Fundação Odebrecht e vendida como a tábua de salvação das crianças e jovens oriundos do povo cearense. Neste sentido, a educação escolar, denominada de cidadã, pelos referidos órgãos e pelos governos, contribui sobremaneira para formar uma subjetividade passiva conformada à realidade, especialmente através da suposta inclusão do chamado cidadão planetário nas malhas das relações sociais, sob a insígnia de indivíduos praticistas de segunda ou terceira classes, servidores passivos do mercado.

\section{Educação e individualidade}

Assentados em Marx, consideramos o indivíduo em sua vida cotidiana e em constante atividade criativa e transformadora. Noutras palavras, analisamos o indivíduo em sua práxis sócio-histórica, intentando elevar nosso pensamento ao ponto em que, pelo exercício da atividade crítica, compreendamos o indivíduo para além do pragmatismo cotidiano, como nos adverte Heller, secundada em Marx, qual seja na forma de um concreto pensado. Desse modo, seguimos a trilha traçada por Marx e Engels, no clássico A ideologia Alemã, buscando nos libertar do empirismo, doutrina pretensamente prática, mas essencialmente abstrata, pois não opera com o concreto pensado, contentando-se com os dados provindos dos sentidos e da “(...) ação imaginária de sujeitos imaginários, tal como é para os idealistas" (MARX e ENGELS, 1989, p. 22).

Lembramos: para Marx, o indivíduo é enraizado na sociedade e a raiz da sociedade é o próprio homem. Destarte, tratamos não de um indivíduo atomizado, nem de robsionadas, como explicam Marx e Engels, na obra a pouco mencionada, pois, como nos adverte Heller, o indivíduo somente existe em sociedade. Deste modo, somos convidados, pela realidade analisada sob a ótica marxista, a compreender o indivíduo não somente em sua vida particular, mas nos marcos das circunstâncias históricas e sociais de produção e reprodução de sua existência. Assim, gênero humano e individualidade, objetividade e subjetividade articulam-se de maneira interdependentes na totalidade complexa da vida social, mediadas de modo dialético pelas relações dos seres humanos entre si e destes com a natureza, especialmente no contraditório mundo do trabalho, mas também nas esferas da ética e da estética.

\begin{tabular}{|l|l|l|l|l|}
\hline Revista Dialectus & Ano 1 & n. 1 & Julho-Dezembro 2012 & p. 46-60 \\
\hline
\end{tabular}


Na esteira de Marx, Vázquez compreende o individuo como ser social e “(...) não (é) um aglomerado de átomos sociais (...)" (VÁZQUEZ, 2008, p. 173), como o apresenta o liberalismo, pois indivíduo e sociedade possuem implicações dialéticas recíprocas.

O filósofo mexicano-espanhol acentua que somente a participação ativa do indivíduo em nome dos interesses coletivos, poderá superar essa separação de interesses entre sociedade e individuo. Isso se dá em condições históricas e sociais específicas e depende dessas mesmas condições para poder realizar-se. Nesse caso, a educação pode contribuir através do trabalho com a herança cultural e com a elevação da consciência crítica dos indivíduos. Entretanto, nos marcos do imediatismo economicista pragmático há uma imposição ao produtivismo, como se a vida fosse mera existência imediata, dessencializando o homem, negando seu ser genérico, reconhecendo-o apenas como ser fabricador e utilizador de instrumentos, relegando o indivíduo a uma vida quase somente física e animal, na qual o pensamento se desenvolve de modo raso e utilitário. Isso resvala em uma prática pedagógica superficial, empobrecedora das capacidades humanas e afeita a uma crítica limitada ao aperfeiçoamento das relações de dominação existentes, aos moldes do (neo)pragmatismo.

Na crítica ao materialismo mecanicista de Feuerbach e ao idealismo hegeliano, Marx e Engels nos ensinam: o indivíduo é um ser ao mesmo tempo teórico e prático, crítico e transformador, capaz de desenvolver potencialidades infinitas de afirmação de sua humanidade. Nesses termos, a educação escolar pode contribuir sobremaneira para a formação integral dos seres humanos em constante crescimento físico e intelectual, de modo a engendrar as condições superadoras dos problemas reais impostos pelas circunstâncias históricas. Corroborando com essa ideia, Vázquez informa: "Segundo Marx, o homem real é, unidade indissolúvel, um ser espiritual e sensível, natural e propriamente humano, teórico e prático, objetivo e subjetivo. O homem é, antes de tudo práxis ( )” (2008, p. 291) e histórico.

Daí decorre nossa recusa à formação do individuo meramente prático, por meio da escola, nos marcos da educação (neo)pragmática, pois, para Vázquez, o pragmatismo americano, por identificar verdade com utilidade ou êxito, representa a nível filosófico uma ética egoísta, ligada ao espírito empresarial e “(...) rejeitando a existência de valores ou normas objetivas, apresenta-se como mais uma versão do subjetivismo e do irracionalismo" (2008, p. 288). 
Desse modo, nossa reflexão não separa o desenvolvimento da individualidade, do processo socializador da educação, nem da crise econômico-social capitalismo hodierno. Intentamos realizar esta análise considerando a totalidade da vida sócio- humana e a riqueza de suas inter-relações. Para atingirmos este fim, perseguimos uma abordagem comprometida em compreender as raízes do fenômeno em questão, na forma de uma totalidade concreta, como nos explica Kosik (1995).

Temos clareza que essa via não é de fácil acesso, pois, vivemos o "Monopólio da aparência" (DEBORD, 1997, p. 17), portanto do pensamento pragmático e vazio de conteúdo. Vivemos sob o domínio de uma concepção filosófica, o (neo)pragmatismo, que reserva à ciência caráter técnico prático-instrumental, focada em resultados, como registra Japiassu (2001). Para o referido autor, o neopragmatismo contextualista de Rorty, ao reabilitar o senso comum, desqualifica a universalidade e toma a verdade como conversação entre sujeitos em consenso localista e prático, comprometendo o conhecimento da verdade.

Por outro lado a filosofia política rortyana, revela-se atrelada aos poderes instituídos pelo capital, conquanto o autor neopragmático assuma a aparência de um intelectual crítico. Liberal assumido, Rorty considera os Estados Unidos como a melhor forma de sociedade existente até hoje. Segundo Japiassu, Rorty

\begin{abstract}
( ) converte-se no ideólogo de uma ética incapaz de tomar o indivíduo como um ser livre e soberano, mas como alguém devendo viver sua liberdade como um simples complemento instrumental dos dispositivos maximizadores das 'vantagens' e 'gozos' individual, realizando espasmodicamente os gestos que lhe impõe o campo sócio-histórico: ganhar dinheiro, levar vantagem, consumir, gozar, etc (JAPIASSU, 2008, p. 144).
\end{abstract}

Além de não acreditar na emancipação, Rorty (1999, p. 130) critica o que considera "Estes esforços fúteis para filosofar ( )". Afirma também que não precisamos fundamentar nada, pois o filósofo deve ser intencionalmente periférico.

Nos moldes do neopragmatismo rortyano, o indivíduo torna-se um consumidor de objetos e um consumidor de ilusões, vivendo uma falsa vida. Uma sobrevida voltada para o aqui e agora, cúmplice com a alienação do presente e sem compromissos com o futuro.

Portanto, defendemos a tese segundo a qual o pragmatismo é a filosofia dos tempos de crise do capitalismo nos quais o indivíduo se vê atacado em seu ser genérico e na sua individualidade, sem autonomia, sem liberdade. Nas condições específicas da crise atual, a formação passou a confundir-se com armazenamento de informações úteis e abreviadas, realizada em cursos à distância e aplicáveis à prática corriqueira, 
mormente em finais de semana ou em período de férias escolares. Nesses, a conceituação da realidade é substituída pela opinião, pela experiência ou pela prática sem fundamentos. Nota-se nesse processo o elogio ao espontaneísmo das falas desligadas dos fundamentos das ciências e da análise profunda da vida real com suas relações contraditórias e conflitantes, fincadas na alienação do cotidiano. Conquanto receba a capa de ensino crítico e participativo, essas práticas educativas ensinam para a obediência aos padrões estabelecidos, para a reprodução da ordem dominante, para a manutenção das relações de exploração de classe, reproduzindo assim, a velha pedagogia dos pobres lincada num fazer limitado e folclórico, afeito a brincadeiras denominadas de ludismo, como denuncia Lepape (1975).

Nesse sentido, na relação entre professor e alunos um elo perdeu-se, pois o sistema descaracterizou a práxis pedagógica, esvaziando-a ao nível do senso comum ao invés de elevar os alunos ao nível do mestre. O caminho apontado pelas práticas pedagógicas da moda, a exemplo das pedagogias do aprender a aprender, é o do rebaixamento da reflexão do professor ao nível infantil. A práxis educativa perde sua maioridade e o professor declina de sua função de ensinar, pois a práxis educativa quedou relativizada, em nível de conhecimento, rebaixada, na medida em que o professor abriu mão de seu papel de organizador e articulador da reflexão crítica acerca do conhecimento acumulado e jogou nas mãos dos alunos a responsabilidade sobre o ato educativo, num cristalino espontaneísmo.

O recuo da teoria, denunciado por Moraes, afeta a formação humana, empobrecendo os indivíduos, comprometendo o acesso ao conhecimento, seja da língua pátria, na qual os alunos demonstram parco condimento da gramática, da literatura e do desenvolvimento da escrita meramente formal e muito menos de uma escrita questionadora e criativa, como da história e da memória histórica, da geografia e da memória geográfica, especialmente numa época de luta pelo espaço geográfico e de redefinições de mapas, como os últimos trinta anos. Ademais, carecem do domínio mínimo das operações lógico-matemática, como do conhecimento físico-químico e, sobretudo da sensibilidade artístico-cultural, pois a lógica da abordagem escolar fundamenta-se nas relações mercadológicas dominantes, obviamente, inumanas.

Quando o objetivo é aprender a fazer para tornar-se útil e quando se prioriza a formação do empreendedor, os fins mercantis justificam os meios e o conhecimento transforma-se em saberes da experiência, práticos, instrumentais, pobremente articulados, superficiais, funcionais.

\begin{tabular}{|l|l|l|l|l|}
\hline Revista Dialectus & Ano 1 & n. 1 & Julho-Dezembro 2012 & p. 46-60 \\
\hline
\end{tabular} 
Longe está o incentivo ao cultivo do espírito, à uma formação cultural sólida, fundamentada no melhor conhecimento histórico, filosófico, artístico e ligado às bases de todas as ciências.

Como nos adverte Saviani, a escola precisa ensinar o conhecimento mais elaborado e em consonância com a vida real do povo e suas necessidades de alimentação, habitação, vestuário, fruição. Para nós, essa escola seria bela, trabalharia o jogo e as brincadeiras, como forma de educar e deveria ser alegre. Além disto, mobilizaria as energias físicas e mentais das crianças e jovens, operando na zona de desenvolvimento próximo, como explica Vigotsky, incentivando a criatividade e elevando o conhecimento.

A escola é um espaço de formação da individualidade, não o lugar de formação do pequeno empresário, do homem de negócios. Dessa forma, a escola funciona como meio de introjeção da lógica competitiva do capitalismo em crise.

Em nosso horizonte, a escola é lugar de formação de sujeitos omnilaterais, ricos de conhecimento, capazes de operar como filósofos, químicos, pedagogos ou médicos, dentre outras profissões, mas sempre senhores de suas decisões conscientes, pois fundamentados em conhecimentos largos, não meramente mecânicos e fragmentados. É ainda lugar da formação de educandos dominadores da ciência e da técnica, sabedores do valor social do conhecimento e pondo-o à serviço da coletividade.

Mas como realizarmos esta proposta, se estamos na era do império dos bancos na educação, inaugurada por volta dos anos 70, do século XX, quando o BM passou a operar de modo mais incisivo no setor educacional, tornando-se uma espécie de ministério mundial da educação dos países periféricos, como registrado por Leher?

Nesta época imperial dos bancos, na educação, destacamos o empenho do Banco Central do Brasil em implantar projetos de educação financeira nas escolas públicas brasileiras, com a participação de bancos privados, como o Unibanco. O que podemos esperar de uma época na qual as instituições financeiras decidem os destinos da educação? A formação ilusória do empreendedor? A propagação da livre iniciativa entre os alunos da escola pública? A divulgação das regras do mercado como as mais adequadas para as relações entre os indivíduos, no caso os alunos filhos dos trabalhadores?

Até aqui nos referimos ao indivíduo prático, que nos marcos do capitalismo se confunde com o individuo praticista, unilateral, fragmentado, partido, como escreve Drummond no poema Nosso Tempo. Na lógica capitalista a prática do indivíduo se 
relaciona à utilidade ligada às necessidades reprodutivas do capital, portanto, relacionada à exploração dos trabalhadores e ao lucro dos patrões. Como demonstra Marx, na extensão de sua obra, o indivíduo só recebe valor enquanto produz valor, embora perca valor à medida que produz mais valor.

Por sua vez, a individualidade emancipada dos grilhões do capital encontraria possibilidades de desenvolvimento sem precedentes, inserida numa práxis relacionada às verdadeiras necessidades humanas. Nesse sentido, a prática diz respeito à cadeia complexa de atividades humanas no processo de constante de humanização dos homens, permitindo um tipo de desenvolvimento omnilateral, sem a imposição de atividades exclusivas, no qual o indivíduo

\footnotetext{
(...) pode se aperfeiçoar no ramo que the agradar (...) o que cria para mim a possibilidade de hoje fazer uma coisa, amanhã outra, caçar de manhã, pescar na parte da tarde, cuidar do gado ao anoitecer, fazer crítica após as refeições, a meu bel prazer, sem nunca me tornar caçador, pescador ou crítico". Assim, teoria e prática corporificam-se num par dialético, promovendo o livre desenvolvimento das potencialidades humanas, certamente ilimitadas (MARX \& ENGELS, 1989, p. 29).
}

Mas, ao contrário, as relações de dominação do capital, materializadas especialmente em grandes corporações transnacionais e em Estados poderosos, impõem ao indivíduo uma vida empobrecida de conteúdo, provocando um vazio teórico paralisador da criatividade, pois, em nome do lucro, o capital produz e reproduz, reduzindo as atividades humanas a simples cópias de modelos, como ocorre na engenharia, na moda, na educação, na indústria cultural e em outros setores. Nesse contexto, reina a mercadoria, personificada em diferentes objetos, como um computador, ou uma cadeira; no corpo humano, posto à exploração, seja nas fábricas ou na prostituição feminina ou masculina, adulta ou infantil; nas drogas mortais, a exemplo do crack; na educação escolar e universitária, dentre outras. No mercado, todas possuem igual estatuto à disposição dos consumidores.

Ao utilitarismo do capital, importa o indivíduo prático, no sentido mais desqualificado ou pobre do termo. Assim, o indivíduo necessita apenas saber fazer algo, ou seja, executar as tarefas determinadas pela hierarquia, garantindo perdas mínimas ou perda zero na produção. Está claro, portanto, que o antiteoricismo pragmático produz o rebaixamento cultural da individualidade exposta à atividade educativa sob suas premissas praticistas e de resultados. 


\section{O pragmatismo educacional e a formação do indivíduo prático}

No contexto do liberalismo deweyano, adotado por Anísio Teixeira, no Brasil, o individuo pragmático insere-se nas relações sociais objetivando aperfeiçoá-las e humanizá-las. Nesse sentido, a educação escolar surge como elemento primordial para formar as subjetividades propícias à sociedade democrática a qual defendem. No formato de uma comunidade em miniatura, a escola redireciona as atividades dos indivíduos de modo a sensibilizá-los para a vida comunitária e a participação cidadã nos organismos sociais.

Em seu percurso idealista, Dewey pretende reatar os liames quebrados entre os indivíduos e a comunidade, apresentando essa cisão como mera disfunção das relações sociais, desconhecendo, como descreve Heller, que, na sociedade burguesa, diante das relações desiguais de classes, “(...) o homem converteu-se em um ser social não necessariamente comunitário, (HELLER, 2004, p. 73). Para a filósofa húngara, o alimento do individualismo burguês é o distanciamento da comunidade. Para Heller, o indivíduo nasce e vive sem vida comunitária, sendo esse, seu ideal de vida, identificado por ele, como liberdade pessoal. Nesse sentido, esclarece Heller, imperam os interesses privados e egoístas do individualismo sobre os interesses gerais e comunitários.

Já na perspectiva de Dewey, há indivíduos desajustados necessitando ser integrados à ordem como pessoas, não como sujeitos vitimados pela lógica corrente e com potencial superador dela. Em consequência, o reformismo pragmático deweyano aponta para ações assistencialistas para os desajustados e complacência para os dominantes, esperando destes atos humanizadores das relações sociais, pelo esclarecimento.

Porém, Para Heller (2004, p. 80),

O homem torna-se indivíduo na medida em que produz uma síntese em seu eu, em que, transforma conscientemente os objetivos e aspirações sociais em objetivos e aspirações particulares de si mesmo e que, desse modo, 'socializa' sua particularidade.

De acordo com a filósofa supracitada, a experiência educativo-comunitária de Makarenko na Colônia Górki, na Rússia revolucionária, ao contrário da comunidade em miniatura de Dewey, representa a possibilidade de encontro do individuo com o gênero humano, pois a experiência de Makarenko apresenta uma comunidade de conteúdo axiológico positivo, na qual os sujeitos encontram possibilidades concretas de

\begin{tabular}{|l|l|l|l|l|}
\hline Revista Dialectus & Ano 1 & n. 1 & Julho-Dezembro 2012 & p. 46-60 \\
\hline
\end{tabular}


desenvolvimento de suas individualidades na comunidade, superando assim o conflito entre interesses individuais e gerais.

$\mathrm{Na}$ esteira de Heller, Duarte (1993) compreende a educação escolar como elo mediador entre as esferas da cotidianidade e as esferas não cotidianas da vida social, ou seja, a arte, a filosofia e a ciência. Dessa feita, a atividade prática do individuo só se eleva ao nível da práxis, quando é atividade humano-genérica consciente, na unidade viva de particularidade e genericidade, ou seja, na cotidianidade, a atividade individual não é mais do que uma parte da práxis, da ação total da humanidade, pois

\begin{abstract}
A individualidade e as formas dos indivíduos se relacionarem estão condicionadas histórica e socialmente. O modo pelo qual produzem ou se inserem no modo de produção, sua vinculação com os órgãos do poder, sua maneira de amar e de enfrentar a morte, seus gostos e preferências estão condicionados socialmente. No indivíduo, se sintetiza toda uma série de relações sociais. (VÁZQUEZ, 1977, p. 331).
\end{abstract}

Ao passo em que o capitalismo investe no praticismo para tentar superar a crise, a profundidade da mesma exige, para superação dos sinuosos problemas criados pelo sistema do capital, abordagens profundas que examinem suas raízes, não somente a superficialidade. Como expressa Kosik, a totalidade concreta é composta de aparência e essência, donde a aparência apresenta elementos de verdade, mas também de enganos. Para apreender a realidade e seus nexos, precisamos romper com a pseudoconcreticidade do fático, das maquiagens, compreendendo o real par além dos jogos de cena ou dos jogos de linguagens. Somente sujeitos com capacidade de análise totalizante, com profundidade de conhecimento da realidade, poderão expressar o caminho de superação da inédita crise a qual vivenciamos neste século XXI, mas herdada das relações de exploração do século passado. Estes defenderão outra lógica de organização social, contrária, portanto, ao esvaziamento da consciência, ao parasitismo do pensamento e a favor da igualdade entre os seres humanos. Essa igualdade pressupõe acesso igualitário e solidário aos bens materais e culturais, por parte de todos os povos, raças e etnias, como o direito inquestionável de viver livremente a individualidade no campo da sexualidade e do prazer, resultando na existência de indivíduos plenamente desenvolvidos.

Acerca da crise capitalista em curso e do esvaziamento do humano, corroboramos com Freitas, quando nos explica:

Não é relevante definirmos quanto tempo ainda tem o capitalismo. O relevante é definirmos quanto tempo nós ainda temos, antes que (...) o sistema desabe sobre nossas cabeças. Não precisamos de rotas de fuga - quando o sistema ruir não haverá para onde fugir. Precisamos de rotas de enfrentamento e combate agora (FREITAS, 2005, p. 107).

\begin{tabular}{|l|l|l|l|l|}
\hline Revista Dialectus & Ano 1 & n. 1 & Julho-Dezembro 2012 & p. 46-60 \\
\hline
\end{tabular}


Nessa época de crise capitalista e de imposição neopragmática, a individualidade alienada domina historicamente a vida sócio-econômica na qual a apropriação privada dos bens matérias e culturais e a exploração dos trabalhadores funcionam como a regra mestra das relações entre os seres humanos. Se na fábrica o trabalhador encontra seu algoz: o patrão e as normas hierárquicas de trabalho, na escola, seus filhos encontram a negação histórica do conhecimento, realizada através de uma série de relações complexas que impedem os filhos dos trabalhadores de acessarem a mais elevada cultura escolar.

Na condição de educadores, precisamos nos unir aos lutadores sociais, objetivando efetivar atividades mediadoras, que, em meio às contradições atuais, garantam aos trabalhadores e aos seus filhos a compreensão crítica das relações sociais vigentes e a necessidade urgente de transformá-las a favor do desenvolvimento de individualidades plenas, construtoras de uma vida nova de sentido emancipador. Lembrando sempre, que, para além do limitado dualismo pragmático, “a vida cotidiana é a vida do homem do homem inteiro: ou seja, o homem participa na vida cotidiana com todos os aspectos de sua individualidade, de sua personalidade" (Heller, 2004, p. 17). Somente como seres inteiros poderemos enfrentar a enorme tarefa de mudar a vida e criar o desenvolvimento superior da individualidade na qual o indivíduo se enlaça com a universalidade humana, portanto, com sua essencialidade.

\section{Referências Bibliográficas}

ANDRADE, Carlos Drummond de. A rosa do povo. São Paulo, SP: Record, 2001.

DEBORD, Guy. A sociedade do espetáculo. Tradução: Estela dos Santos Abreu. Rio de Janeiro: Contraponto, 1997.

DEWEY, John. Democracia e educação. Introdução à filosofia da educação. Tradução: Godofredo Rangel e Anísio Teixeira. São Paulo: Companhia Editora Nacional, 1959.

DUARTE, Newton. A individualidade para si. Contribuição a uma teoria históricosocial da formação do indivíduo. Campinas, SP: Editora Autores Associados, 1993 (coleção educação contemporânea).

FREITAS, Luis. Carlos de. Uma pós-modernidade de libertação. Reconstruindo as esperanças Campinas, SP: Autores Associados, 2005. (Coleção Polêmicas do Nosso tempo). 
HELLER, Agnes. O cotidiano e a história. Tradução: Carlos Nelson Coutinho e Leandro Konder. Rio de Janeiro: Paz e Terra, 2004.

INSTITUTO DE CO-RESPONSABILIDADE PELA EDUCAÇÃO-ICE. Modelo de gestão - Tecnologia Empresarial Socioeducacional (TESE). Uma Nova Escola para a Juventude Brasileira. Escolas de Ensino Médio em Tempo Integral. Recife, PE. Disponível em: www.ccv.ufc.br/newpage/seduc2010/seduc_prof/dowload/manual_Modelogestao.pdf Acesso: 10/10/2011.

JAPIASSU, Hilton. Nem tudo é relativo. A questão da verdade. São Paulo: Editora Letras \& Letras, 2001.

KOSIK, Karel. Dialética do concreto. Tradução: Célia Neves, Alderico Toríbio. São Paulo: Paz e Terra, 1995.

LEHER, Roberto. Da ideologia do desenvolvimento à ideologia da globalização: a educação como estratégia do Banco Mundial para "alívio à pobreza". 1998. Tese (Doutorado em Educação). Faculdade de Educação, Universidade de São Paulo, São Paulo.

LEPAPE, Marie. Claire. Pedagogia e Pedagogias. Tradução de Agostinho Trindade de Sousa. [S.1.]. Empresa Norte editora, biblioteca 70, 1975.

MARX, Karl; ENGELS, Friedrich. A ideologia Alemã. Tradução: Luis Claudio de Castro e Costa. São Paulo: Martins Fontes, 1989.

1992. Textos sobre educação e ensino. São Paulo: editora Moraes,

MÉSZÁROS, István. Produção destrutiva e estado capitalista. São Paulo: Ensaio, 1989.

Para além do capital. Tradução: Paulo Sérgio Castanheira, Sérgio Lessa. São Paulo: Boitempo; Campinas: Editora da UNICAMP, 2002.

O século XXI: Socialismo ou barbárie? Tradução: Paulo César Castanheira. São Paulo: Boitempo Editorial, 2003.

Paulo: Boitempo, 2005.

A educação para além do capital. Tradução: Isa Tavares. São

MORAES, Maria. Célia. Marcondes de. (Org.) Iluminismo às avessas. Produção de conhecimento e políticas de formação docente. Rio de janeiro, DP\&A, 2003.

POCHMANN, Marcio. Transformações do capitalismo. IN: Le Monde diplomatique Brasil. São Paulo, SP: Instituto Pólis, Ano 5, n. 51, pág. 6, 7, Out. 2011.

REVISTA ÉPOCA. Dívida da zona do euro diminui no $3^{\circ}$ trimestre de 2011.

Disponível em www.epocanegocios.globo.com/revista. Acesso: 10/02/2012.

\begin{tabular}{|l|l|l|l|l|} 
Revista Dialectus & Ano 1 & n. 1 & Julho-Dezembro 2012 & p. 46-60 \\
\hline
\end{tabular}


RORTY, Richard. Para realizar a América: o pensamento de esquerda no século XX na América. Tradução: Paulo Ghiraldelli Jr., Alberto Tosi Rodrigues e Leoni Henning. Rio de Janeiro: DP\&A Editora, 1999.

SAVIANI, Dermeval. História das ideias pedagógicas no Brasil. Campinas: SP: Autores Associados, 2007 (Coleção memória da educação).

VÁZQUEZ, Adolfo Sánchez. Filosofia da práxis. Tradução: Luis Fernando Cardoso. Rio de Janeiro: Paz e Terra, 1977.

Ética. Tradução: João Dell'anna. Rio de Janeiro: Civilização

Brasileira, 2008. 